\title{
Особенности функционирования английского фразеологизма «под тенью» в контексте угрозы
}

\author{
Храброва В.Е. \\ Национально-исследовательский университет «Высшая школа экономики» \\ Россия, 192211, г. Санкт-Петербург, ул. Кантемировская, д. 3, литера А \\ E-mail: stefankhrabrova@mail.ru
}

\begin{abstract}
Аннотация. Представлен анализ английской фразеологической единицы (ФЕ) under the shadow of с целью выявления особенностей ее функционирования в предложениях и словосочетаниях в контексте угрозы. Материалом исследования служит выборка данных из Британского Национального Корпуса и корпуса iWEB. Выбранная ФЕ рассматривается как единица вторичной номинации с коннотацией «под негативным воздействием; под угрозой». Образность внутренней формы фразеологизма обусловлена его основным компонентом shadow (тень), который олицетворяет собирательный образ-символ ущербных черт человеческой личности. $\mathrm{C}$ опорой на структурно-грамматический анализ определен грамматический статус исследуемой единицы как фразеологического предлога (ФП). Дистрибутивный метод используется для определения сочетаемости элементов фразеологизма на синтаксическом и лексическом уровнях и позволяет констатировать расширение и усложнение их структуры. Выявлено, что это достигается с помощью включения в состав ФП дополнительных лексических и синтаксических средств создания большей экспрессивности текста. Данные контекстного анализа корпусов свидетельствуют о широком использовании исследуемой единицы в менасивном контексте для демонстрации автором негативного отношения к неблаговидным явлениям и событиям и создания общественного резонанса. Таким образом, сделан вывод о большом прагматическом потенциале исследуемого фразеологизма как инструмента имплицитного воздействия на человеческие эмоции.
\end{abstract}

Ключевые слова: тень, фразеологический предлог, прагматическая функция, менасивный, коннотация, пейоративный, оценочная семантика.

Для цитирования: Храброва В.Е. 2020. Особенности функционирования английского фразеологизма «под тенью» в контексте угрозы. Вопросы журналистики, педагогики, языкознания, 39 (4): 652-661. DOI 10.18413/2712-7451-2020-39-4-652-661

\section{Peculiar Functioning Features of the English Idiom «Under the Shadow» in Destructive Context}

\author{
Valentina E. Khrabrova \\ National Research University Higher School of Economics (HSE) \\ 3A Kantemirovskaya St, St Petersburg, 194100, Russia
}

\begin{abstract}
The article aims to research the idiom under the shadow of with the view to revealing the main peculiarities of its functioning in sentences and complex collocations in menacing discourse. The method of object-oriented sampling is employed to select materials from the British National Corpus (BNC), the Intelligent Web-based Corpus (IWeb), articles, their titles, books, whose choice is determined by their deteriorative evaluative relatedness. Based on the lexicographic method, we define the meaning of the analyzable idiom as «under the bad effect or influence that something has, which makes other things less enjoyable, attractive or impressive and be dominated by». The quantitative method of processing the corpus data enables the curtailment of selected research material from 500 to 121 units, due to the
\end{abstract}


criterion of their compulsory attribution to deteriorative discourse. The distributive method is used to observe the components of the idiom in terms of syntactic and lexical co-occurrence and interaction within a sentence or phrase. The structural-grammatical analysis of the idiom reveals its role as a cohesive element, whereby other subordinate parts of a sentence or phrase are joined together to manifest adverbial and attributive relations therein. The idiom is regarded as a lexical support of the postpositional bundle of words and their semantical intensifier. The researched lexical unit accomplishes the pragmatic function, thereby conveying various negative connotations. The uppermost connotation of negative influence stems from the main deteriorative constituent shadow, which accounts for auctorial emotional expression towards indiscretions and terrible manifestations in the global world. From the obtained findings, it can be inferred that the phraseological unit under the shadow of comes across as an effective pragmatic device in sentences and headings of aggressive, threatening orientation, namely menace, reprimand, condemnation, allegation, and the like. The idiom exhibits a number of stylistic features of enhancing the emotional impact on readers by means of effective linguistic devices.

Keywords: shadow, phraseological preposition, pragmatic function, menacing, connotation, deteriorative, appraisive semantics.

For citation: Khrabrova V.E. 2020. Peculiar Functioning Features of the English Idiom «Under the Shadow» in Destructive Context. Issues in Journalism, Education, Linguistics, 39 (4): 652-661 (in Russian). DOI 10.18413/2712-7451-2020-39-4-652-661

\section{Введение}

Оценка событий окружающего мира в широком смысле слова проходит сквозь призму дихотомии хорошо - плохо, положительно - отрицательно, морально - аморально, социально - асоциально [Лескина, 2009] и отражает антропологическую природу фразеологических единиц (ФЕ). Язык есть орудие общения и воздействия, которое управляет поведением человека с помощью прагматически нагруженных языковых единиц, в частности ФЕ. По мнению М.М. Рыжковой, «ФЕ изначально предназначены для воздействия на психологическое состояние читателя, регуляции его поведения и способствуют реализации авторского замысла» [Рыжкова, 2008, с. 9].

Цель данной работы состоит в исследовании фразеологической единицы under the shadow of и выявлении особенностей ее прагматического функционирования, т.е. способности оказывать непосредственное воздействие на эмоции и поведение получателя информации (адресата) и формировать у него прагматическое отношение к событиям преимущественно менасивной направленности. В нашей работе мы опираемся на следующие теоретические положения: о прагматике как закрепленному в языковой единице отношению говорящего к действительности, содержанию информации, адресату; о способности языковых знаков производить «определенное впечатление на людей и вызывать различные эмоциональные реакции, личное (прагматическое) отношение к информации» [Рыжкова, 2005, с. 112]. Как вторичная номинация рассматриваемая нами ФЕ подвергается лингвистическому анализу впервые, хотя ее ключевой компонент shadow (тень) можно причислить к объектам пристального научного изучения в разных областях знаний.

В исследовании использован комплекс методов и приемов: анализ лексикографических источников; целенаправленная выборка материала для исследования из данных языковых корпусов; квантитативная обработка выбранных корпусных данных; метод эмпирического исследования для классификации различных видов контекста; метод контекстного анализа для изучения условий реализации значения исследуемой языковой единицы; описание и обобщение полученных данных: группировка, классифицирование; дистрибутивный метод для определения сочетаемости элементов на синтаксическом и лексическом уровнях языка [Бузальская, Любимова, 2016].

В начале работы необходимо определить наше понимание категории «фразеологические единицы», учитывая актуальность и неоднозначность этой научной проблемы. 
К категории фразеологизмов мы причисляем полностью или частично переосмысленные по значению раздельнооформленные единицы языка, обладающие устойчивостью, семантической осложненностью, постоянством лексического состава, морфологической и синтаксической фиксированностью, а именно: идиомы - собственно фразеологизмы, фразеологические сочетания, речевые штампы, клише и цитаты, сочетания служебных слов с идиоматичностью значения, паремии - пословицы и поговорки [Арсентьева, 1989; Василенко, 2011]. Принимая во внимание системные отношения элементов языка [Кунин, 1996], мы причисляем исследуемый фразеологизм к разряду номинативных (предложных) фразеологических единиц.

Материалом для исследования послужили предложения и заголовки с $\Phi \mathrm{E}$ under the shadow of, полученные методом целенаправленной выборки из базы данных Британского Национального Корпуса (British National Corpus - BNC), IWeb Intelligent Web-based Corpus [The iWeb corpus], научных статей и книг. На базе корпуса BNC составлен авторский банк из 500 предложений и развернутых словосочетаний с исследуемым фразеологизмом.

Согласно словарю Longman [Procter, Ilson, 1981, p. 1505], выбранная ФЕ under the shadow of означает «under the bad effect or influence that something has, which makes other things less enjoyable, attractive or impressive»- под негативным воздействием / влиянием со стороны чего-то / кого либо, что делает вещи менее приятными, непривлекательными. Словарь идиом определяет значение обсуждаемого фразеологизма как to be dominated by [Spears, 2000, p. 55] - находиться под господством, во власти кого-либо или чего-либо, например: his country has been under the shadow of totalitarianism for decades / его страна десятки лет находится под пятой тоталитаризма.

\section{Результаты и их обсуждение}

Рассмотрим исследуемую ФЕ со структурно-грамматической точки зрения [Шиганова, 2014]. Современные лингвистические исследования опираются на принцип системного описания отдельных частей лексико-фразеологического фонда языков, в том числе английского языка. Ученые-лингвисты выделяют класс единиц категориальной релятивной семантики, включающий фразеологические предлоги (ФП), изучение которых в науке либо велось «бессистемно в направлении текст - система, т.е. от непосредственно наблюдаемых структурных и синтагматических свойств предлогов к установлению их парадигматических значимостей и интерпретации их значений в речи» [Шиганова, 2014, с. 269], либо до сих пор остается вне поля зрения исследователей. Г. А. Шиганова [2014] подчеркивает важность изучения таких единиц, в том числе ФЕ under the shadow of, в целях познания сложной системы языка, отражающей результаты человеческого мышления. В английском языке известные предлоги являются лексическими аналогами ФП, например: because - in view of the fact that (ввиду), near - in the vicinity of (вблизи), about - on the subject of (o), despite / in defiance of (вопреки), due to - under the shadow of (под отрицательным влиянием - воздействием). Как отмечает Г.А. Шиганова, ФП превратились «в средство разгрузки лексических предлогов, которые в силу своей многозначности не могут дифференцированно выражать те или иные виды отношений в языке» [Шиганова, 2014, с. 270]. По этой причине ФП также называются релятивными (относительными) фразеологизмами, т.е. фразами с собственным значением и сходными семантическими свойствами соотнесенных с ними лексических предлогов. Являясь частью системы языка, они «вступают в диалектическое взаимодействие между собой и с единицами других семантикограмматических классов» [Шиганова, 2014, с. 269], выполняя связующую функцию [Кунин, 1996].

В трудах лингвистов отмечена высокая частотность словосочетаний с предлогом of в английском языке, которая составляет примерно 70 \% общей частотности всех предложных английских словосочетаний. Выявлено, что использование данных предложных еди- 
ниц характерно для всех стилей речи: «на страницу печатного текста объемом 23002500 знаков приходится от 1 до 16 речевых отрезков с предлогом of в художественном творчестве и 3-17 в научной прозе» [Сучкова, 1998, с. 5]. Согласно статистике British National Corpus [BNC], самая высокая частотность under the shadow of наблюдается в беллетристике (13), неакадемическом (9) и академическом (7), газетном (5) стилях английского языка. Из 500 исследованных корпусных предложений и фраз для анализа отобраны 121 $(24 \%)$ на основании их соотнесенности с основным критерием - отрицательным субъективно-оценочным компонентом [Арсентьева, 1989, с. 47].

Одной из функций анализируемой ФЕ, как уже отмечалось выше, является прагматическая функция - «целенаправленное воздействие языкового знака на адресата» [Кунин, 1996, с. 60]. В этой связи к важной составляющей использования ФЕ under the shadow of в контексте можно отнести возможность сообщения читателям дополнительного оттенка содержания, которое выходит за пределы семантики сочетающихся слов. Такое свойство является неотъемлемой частью семантической структуры данного фразеологизма - элементом коннотативного аспекта, стоящего на службе передачи эмоций и формирования оценки описываемых явлений в рамках шкалы положительно/отрицательно, что крайне необходимо для характеристики описываемого лица или явления. Under the shadow of можно отнести к сочетаниям с присущей (ингерентной) экспрессивностью значения [Сучкова, 1998], причем коннотативность проявляется как у главного компонента shadow, так и у присоединяемой к нему посредством предлога of зависимой фразы: under the shadow of a suicide bombing and a mass shooting / под угрозой взрыва бомб террористамисмертниками и массовых убийств [iWeb Corpus].

Опираясь на понятие о «максимальной коннотативной емкости» [Сучкова, 1998, c. 114], предполагающей возможность образования свободных словосочетаний, в которых соединены понятия, «несовместимые в экстралингвистической реальности», мы наблюдаем образную мотивированность высказываний с исследуемым фразеологизмом, например: under the shadow of a dark cloud of doubts (в тени облака сомнений); paradise is under the shadow of the swords (рай пребывает под сенью клинка); under the shadow of the digital Leviathans (под тенью цифровых левиафанов) [iWeb Corpus]. Анализ предложений c ФE under the shadow of выявляет высокую частотность его использования с глаголом live, что позволяет усилить экспрессию воздействия на читателя: these men are career criminals who live under the shadow of the gallows every day / эти люди - закоренелые преступники, которые каждый день живут под сенью виселицы.

Помимо коннотативной емкости фразеологизм under the shadow of демонстрирует емкость синтаксической синтагматики, то есть возможности расширения и усложнения структуры синтаксическими средствами, нацеленными на создание большей экспрессивности текста. Это достигается с помощью определений (прилагательных с отрицательной семантикой): dark, harsh, mysterious, looming, damned, ominous, sinister; зависимых компонентов фразеологизма (существительных) в составе фразеологизма: death, slaughterhouse, war, extremism, grief, economic slowdown, nuclear holocaust; именем собственнымэвфемизмом: growing up under the shadow of Jim Crow [British National Corpus].

Лингвисты признают неразрывную связь оценки с прагматической функцией языка, так как она служит выражением положительного или отрицательного отношения говорящего к описываемым предметам, событиям или явлениям окружающей действительности. Оценка имеет социальную обусловленность, а ее формирование зависит от норм и оценочной шкалы, принятых в том или ином обществе или его части на определенном отрезке времени. Так как ведущим фактором при выделении оценочных высказываний является «коммуникативная цель суждения, его смысловое задание, а не формальная синтаксическая структура с определенным лексическим наполнением», мы руководствуемся определением языкового выражения оценки как оценочного суждения (высказывания), в котором субъектом выражено свое позитивное или негативное отношение к окружающе- 
му миру, определяемое совокупностью объективных и субъективных факторов [Старостина, 2007].

В данной работе оценочный элемент выбранной ФЕ рассматривается как часть экспрессивного компонента коннотации и принадлежности еe к функциональносемантическому полю пейоративной оценки. Под пейоративностью мы понимаем способность языковых единиц к реализации семантики неодобрения, презрения и порицания, критики в адрес тех лиц, чьи пороки, недостатки, заблуждения, поступки, поведение, которые, выходя за рамки общественной морали, наносят этический, моральный или физический ущерб другим лицам и вызывают отрицательные эмоциональные реакции [Лескина, 2009].

Анализ оценочных суждений с лингвистической точки зрения, по мнению Е.В. Коваленко, указывает на свойства оценки отражать характер отношения человека к миру, причем «основную оценочную нагрузку в языке несут лексические единицы <..> оценочной семантики, а формализация оценочных отношений в языковой системе происходит на уровне синтаксиса» [Коваленко, 2017, с. 24]. Синтаксические конструкции с оценочным значением всегда включают лексические единицы оценочной семантики, которые в нашей работе представлены фразеологическим предлогом under the shadow of, функционирование которого рассматривается далее в контексте угрозы, осуждения, порицания, разоблачения.

В контексте угрозы исследуемая ФЕ рассматривается как элемент менасивной лексики. Отметим, что помимо символических, общих угроз, по способу воздействия на коммуникантов в научной литературе выделены конкретизируемые угрозы для выражения намерений осуществить физическую расправу, ввести экономические и политические санкции, подвергнуть судебному преследованию, запугать промышленной и военной мощью, совершать террористические акты и другие неблаговидные деяния [Эпштейн, 2011]. Рассмотрим примеры конкретизируемых угроз.

Угроза терроризма. It is a grim but inescapable fact that our world lives under the shadow of global terrorism [iWeb Corpus] / Мрачным, но неотвратимым фактом является то, что на нашем мире лежит тень глобального терроризма.

Угроза болезней (например, коронавируса). Заголовок статьи в газете The Diplomat, написанной до официального объявления глобальной пандемии коронавируса, привлекает внимание читателей к нависшей над отдельной страной проблеме: Everyday life in China under the shadow of Coronavirus / Каждый день в Китае под мрачной угрозой коронавируса [Girard, 2020].

Угроза санкций. The Republic of China in Taiwan has taken measures in ecological and environmental protection in keeping with the aforementioned international conventions, but was forced to live under the shadow of trade sanctions imposed by the Protocol / Китайская Республика на Тайване приняла меры в области экологии и защиты окружающей среды в соответствии с указанными выше международными конвенциями, вынужденно оставаясь, однако, в положении страны, в отношении к которой могут быть применены торговые санкции, установленные Протоколом [iWeb Corpus].

Угроза военной мощи, оружия, распространения ядерного оружия. Despite significant progress in international efforts towards the goal of a nuclear-weapon-free world, the Korean peninsula is still living under the shadow of nuclear proliferation / Несмотря на значительный прогресс в международных усилиях по достижению мира, свободного от ядерного оружия, Корейский полуостров по-прежнему живет под угрозой ядерного распространения [iWeb Corpus].

Угроза экологической катастрофы. The ongoing crises - the financial crisis, the crisis in food security under the looming shadow of climate change, and the crisis of human rights and security may reverse some of the advances achieved in 1995 / Нынешние кризисы финансовый кризис, кризис в области продовольственной безопасности под тенью грозно 
нависшей проблемы изменения климата и кризис в области прав человека и безопасности - могут обратить вспять некоторые из завоеваний, достигнутые в 1995 году [iWeb Corpus].

Угроза безработицы. Their families are currently living under the shadow of longterm unemployment; a crash program is needed to build up the economy / В настоящее время их семьи живут под угрозой долгосрочной безработицы; для создания экономики необходима программа [iWeb Corpus].

Осуждение (предание гласности отрицательной оценке) [Дубровская, 2014]. В статье под заголовком «Under the Shadow of Trump: Portrayals of Undocumented Youth in Young Adult Fiction from 2016-2017» / «В тени Трампа: представления о нелегальной молодежи в художественной литературе для юношества с 2016 по 2017 годы» осуждается отношение американского президента к лицам латиноамериканского происхождения, которых он презрительно называет словом Latinx, а также population of criminals, rapists, drug dealers, animals [Salas, 2018].

Порицание подразумевает упоминание выходящих за рамки общепринятых в обществе или узком круге общения моральных норм действий личности, таких как преступления и правонарушения [Дубровская, 2014). В процессе порицания говорящий субъект выражает свое «негативное отношение к действиям объекта в сложившейся ситуации и использует образ определенных стереотипных ситуаций, «сценариев», составляющих ассоциативно-образные основания или мотивы анализируемого концепта и отражающих мотивационный компонент фразеологического значения» [Залавина, 2007, с.19]: Support for the implementation of the Convention to Combat Desertification is urgently called for in light of the fact that globally, more than 900 million people live under the shadow of desertification and drought / Поддержка осуществления Конвенции по борьбе с опустыниванием настоятельно необходима в свете того факта, что во всем мире более 900 миллионов человек живут в условиях угрозы опустынивания и засухи [iWeb Corpus].

Разоблачение проявляется в желании предать гласности отрицательную оценку, вывести кого-либо на чистую воду, представить истинное лицо объекта оценки, которая не всегда совпадает или противоречит общепринятому положительному или нейтральному мнению; намерение человека раскрыть сокровенное, вопреки своему желанию, в силу обстоятельств: In the Security Council, they use the power of the United Nations to protect their interests and to terrorize and intimidate the Third World, causing it to live under the shadow of terror / В Совете Безопасности они используют авторитет Организации Объединенных Наций для отстаивания своих интересов и для того, чтобы терроризировать и запугивать «третий мир», вынуждая его жить в постоянном страхе [iWeb Corpus].

На наш взгляд, пристального внимания заслуживает широкое использование исследуемого фразеологизма в качестве экспрессивного компонента и элемента hook effect (информационного повода) [Кульчицкая, 2014] в заголовках научно-популярных и научных статей, книг на актуальные темы: Nepalese women under the shadow of domestic violence / Женщины Непала под угрозой домашнего насилия [Dhakal, 2008]; название книги: Under the shadow of the swastika: The moral dilemmas of Resistance and Collaboration in Hitler's Europe / Под тенью свастики: моральные дилеммы Движения Сопротивления и сотрудничества с врагом в гитлеровской Европе [Bennett, 1999]; Valuing life under the shadow of death / Цена жизни под угрозой смерти [Bommier, 2003]; Gender rights under the shadow of jihad / Гендерные права под негативным влиянием джихада [Ispahani, 2016]; Victim-Offender Mediation in Germany under the Shadow of the Criminal Law/Содействие в спорах типа жертва-правонарушитель в Германии под негативным влиянием криминального закона [Trenczek, 2004]; Under the shadow of genocide: Rwandans, ethnicity and refugee status/ В тени геноцида: руандийцы, этничность и статус беженца [Jaji, 20017]; Under the Shadow of Napoleon: French Influence on the American Way of Warfare from the War 
of 1812 to the Outbreak of WWII / В тени Наполеона: влияние Франции на способы ведения войны по-американски с 1812 до начала второй мировой войны [Bonura, 2012].

\section{Заключение}

На основании вышеизложенного мы пришли к выводу, что семантические признаки слова shadow, основного компонента анализируемой ФЕ, такие как скрытость, двойничество, неоднозначность, связь с границей между жизнью и смертью предопределяют создание фразеологизмом экспрессивного эффекта в менасивном контексте, что позволяет передать читателям дополнительный, выходящий за пределы значения слов оттенок содержания авторского сообщения.

Приведенные в работе примеры демонстрируют эффективное функционирование мотивационного компонента семантической структуры фразеологизма under the shadow of, а также высокую образность его внутренней формы. Способами передачи образности в выбранном нами исследовательском материале являются сочетания препозитивных прилагательных с основным компонентом «shadow» (under the looming shadow of); сочетания исследуемого фразеологизма с глаголом live, в результате чего образуется оксюморон (coчетание противоречивых слов) «жить под тенью»: living in poverty and under the shadow of slavery; метафора для создания ярких образов (under the shadow of a great hatred); расширенные и усложненные синтаксические структуры как результат присоединения длинной зависимой фразы: under the shadow of the 1929 New York stock market crash.

Со структурно-грамматической точки зрения исследуемый фразеологический предлог, реализуя свою основную функцию связи элементов внутри предложения или фразы, в отличие от стилистически нейтральных лексических предлогов, автономно усиливает экспрессивность всего высказывания за счет образной внутренней формы; с другой стороны, двойная экспрессия сообщения достигается за счет вхождения в его состав эмоционально окрашенных зависимых таких слов, как реалий - under the shadow of two World Wars, under the shadow of Jesus Christ crucified; эвфемизмов - under the shadow of Jim Crow.

Таким образом, семантика основного компонента исследуемого фразеологизма, его внутренняя образная форма, структурно-грамматические свойства и способность сочетаться с эмоционально-окрашенными лексическими единицами демонстрируют высокую прагматическую нагрузку. Присутствие фразеологизма в высказываниях о явлениях и действиях деструктивного характера - угрозы войны, распространения ядерного оружия, санкций, болезней - вызывает у получателей информации отрицательные эмоциональные реакции.

В исследовании также выявлен факт широкого использования under the shadow of как элемента приема hook effect в заголовках статей из журналов, названиях книг для привлечения читательской аудитории к оценочному обсуждению актуальных событий.

\section{Список источников}

1. Bennett R. 1999. Under the shadow of the swastika: The moral dilemmas of Resistance and Collaboration in Hitler's Europe. Palgrave Macmillan. E-book. Available at: https://www.palgrave.com/gp/book/9780333656020 / (accessed: 13 October 2020).

2. Bommier A. 2003. Valuing life under the shadow of death. WP LEA\# INRA, 03-01.

3. Bonura M. 2012. Under the Shadow of Napoleon: French Influence on the American Way of Warfare from the War of 1812 to the Outbreak of WWII, Vol. 3. NYU Press, 318 p.

4. British National Corpus (BNC). 2015. Available at: https://www.english-corpora.org/bnc/ (accessed: 16 October 2020).

5. Dhakal S. 2008. Nepalese women under the shadow of domestic violence. In: The Lancet, 371 (9612): 547-548. DOI: https: //doi.org/10.1016/S0140-6736 (08) 60254-8 
6. Ispahani F. 2016. Women and Islamist extremism: Gender rights under the shadow of jihad. The Review of Faith \& International Affairs, 14 (2): 101-104.

7. Jaji R. 2017. Under the shadow of genocide: Rwandans, ethnicity and refugee status. Ethnicities, 17 (1): 47- 65. DOI: https://doi.org/10.1177/1468796815603754

8. Procter P., Ilson R. F. 1981. Longman Dictionary of Contemporary English. - Harlow, England, Longman, $2224 \mathrm{p}$.

9. Salas R.G. 2018. Under the Shadow of Trump: Portrayals of Undocumented Youth in Young Adult Fiction from 2016-2017. In: Forum on Public Policy Online. Oxford Round Table. 406 West Florida Avenue, Urbana, IL 61801, 2018 (1): 1-14. Available at: https://files.eric.ed.gov/fulltext/EJ1193598.pdf (accessed: 13 October 2020).

10. Spears R.A. 2000. NTC's Dictionary of American Slang and Colloquial Expressions. New York, National Textbook Company, McGraw-Hill, 577 p.

11. The iWeb corpus. 2018. Available at: https://www.english-corpora.org/iweb (accessed 15.12.2019).

12. Trenczek T. 2001. Victim-Offender Mediation in Germany-ADR under the Shadow of the Criminal Law? Bond Law Review: 13 (2), Article 6. Available at: http://epublications.bond.edu.au/blr/vol13/iss2 (accessed: 13 October 2020).

\section{Список литературы}

1. Амосова Н.Н. 1963. Основы английской фразеологии. Ленинград, Изд-во Ленингр. унта, $206 \mathrm{c}$.

2. Арсентьева Е.Ф. 1989. Сопоставительный анализ фразеологических единиц (на материале фразеологических единиц, семантически ориентированных на человека, в английском и русском языках). Под ред. Р.А. Юсупова. Казань, Изд-во Казанского университета, 128 с.

3. Бузальская Е.В., Любимова Н.А. 2016. От приёма к методу: как пройти этот путь с минимальными потерями. СПб., Златоуст, 96 с.

4. Василенко А.П. 2011. Аспекты семантики фразеологизмов (на материале русского и французского языков). Автореф. дис.... докт. филол. наук. Орел, 44 с.

5. Дубровская Т.В. 2014. Речевые жанры «осуждение» и «обвинение» в русской и английской лингвокультурах. Пенза, Изд-во ПГУ, 272 с.

6. Залавина Т.Ю. 2007. Когнитивно-прагматические аспекты фразеологизмов со значением «порицание». Автореф. дис.... канд. филол. наук. Челябинск, 25 с.

7. Коваленко Е.В. 2017. Языковая актуализация пейоративной оценки (на материале английского языка). Новосибирск, НВИ войск нац. гвардии, 121 с.

8. Кунин А.В. 1996. Курс фразеологии современного английского языка. М., Высшая школа; Дубна, Издательский центр Феникс, 381 с.

9. Лескина С.В. 2009. Русские и английские фразеологизмы пейоративной семантики как отражение языковой картины мира. Челябинск, Изд-во ООО Атоксо, 147 с.

10. Рыжкова М.M. 2005. Коммуникативно-прагматические особенности функционирования фразеологических единиц в тексте. В кн.: Когнитивно-прагматические аспекты функционирования языка и дискурса в общетеоретическом и сопоставительном плане. Под ред. Е.Н. Азначеевой. Челябинск, Изд-во ЧГУ: 112-113.

11. Рыжкова М.M. 2008. Передача прагматической составляющей образных фразеологических единиц в публицистическом тексте (на материале английского и русского языков). Автореф. дис. ... канд. филол. наук. Тюмень, 22 с.

12. Старостина Ю.С. 2007. Интерпретация лингвистической оценки в терминах аксиологических суждений. Вестник Самарского государственного университета, 3 (53): 232-240.

13. Сучкова С.А. 1998. Субстантивное словосочетание с предлогом ОF в динамике высказывания. Дис....канд. филол. наук. Самара, 152 с.

14. Шиганова Г.А. 2014. Основные принципы создания семантико-грамматического словаря фразеологических предлогов. Проблемы истории, филологии, культуры, 3(45): 269-271.

15. Эпштейн О.В. 2010. Прагматические особенности менасивного речевого акта в политическом дискурсе (на материале английского языка). Автореферат дис. .... канд. филол. наук. Москва, 20 с. 
16. Girard B. 2020. Everyday Life in China under the Shadow of Coronavirus. Available at: https://thediplomat.com/2020/02/everyday-life-in-china-under-the-shadow-of-coronavirus (accessed: 18 February 2020).

17. Kulchitskaya D.Yu. 2014. Multimedia text in journalism: an analysis of Russian and American mass media. In: World of Media. Yearbook of Russian Media and Journalism Studies: Ed.: E.L. Vartanova, Moscow, Lomonosov Moscow State University: 265-275.

\section{References}

1. Amosova N.N. 1963. Osnovy anglijskoj frazeologii [Fundamentals of English Phraseology]. Leningrad, Publ. Leningr. un-ta, 206 p.

2. Arsent'eva E.F. 1989. Sopostavitel'nyj analiz frazeologicheskih edinic (na materiale frazeologicheskih edinic, semanticheski orientirovannyh na cheloveka, v anglijskom i russkom jazykah) [Comparative analysis of phraseological units (on the material of phraseological units, semantically oriented to a person, in English and Russian)]. Ed. R.A. Jusupov. Kazan', Publ. Kazanskogo universiteta, $128 \mathrm{p}$.

3. Buzal'skaja E.V., Ljubimova N.A. 2016. Ot prijoma k metodu: kak projti jetot put' $\mathrm{s}$ minimal'nymi poterjami [From reception to method: how to go this way with minimal losses]. SPb., Publ. Zlatoust, $96 \mathrm{p}$.

4. Vasilenko A.P. 2011. Aspekty semantiki frazeologizmov (na materiale russkogo i francuzskogo jazykov) [Aspects of the semantics of phraseological units (based on the Russian and French languages)]. Abstract. dis.... doct. philol. sciences. Orel, $44 \mathrm{p}$.

5. Dubrovskaja T.V. 2014. Rechevye zhanry «osuzhdenie» i «obvinenie» v russkoj i anglijskoj lingvokul'turah [Speech genres "condemnation" and "accusation" in Russian and English linguocultures]. Penza, Publ. PGU, 272 p.

6. Zalavina T.Ju. 2007. Kognitivno-pragmaticheskie aspekty frazeologizmov so znacheniem «poricanie» [Cognitive and pragmatic aspects of phraseological units with the meaning of "censure"]. Abstract. dis.... cand. philol. sciences. Cheljabinsk, 25 p.

7. Kovalenko E.V. 2017. Jazykovaja aktualizacija pejorativnoj ocenki (na materiale anglijskogo jazyka) [Linguistic updating of pejorative assessment (based on the English language)]. Novosibirsk, Publ. NVI vojsk nac. gvardii, $121 \mathrm{p}$.

8. Kunin A.V. 1996. Kurs frazeologii sovremennogo anglijskogo jazyka [Course of phraseology of modern English]. M., Publ. Vysshaja shkola; Dubna, Publ. Izdatel'skij centr Feniks, 381 p.

9. Leskina S.V. 2009. Russkie i anglijskie frazeologizmy pejorativnoj semantiki kak otrazhenie jazykovoj kartiny mira [Russian and English phraseological units of pejorative semantics as a reflection of the linguistic picture of the world]. Cheljabinsk, Publ. Izd-vo OOO Atokso, $147 \mathrm{p}$.

10. Ryzhkova M.M. 2005. Kommunikativno-pragmaticheskie osobennosti funkcionirovanija frazeologicheskih edinic $\mathrm{v}$ tekste [Communicative and pragmatic features of the functioning of phraseological units in the text]. In: Kognitivno-pragmaticheskie aspekty funkcionirovanija jazyka i diskursa $\mathrm{v}$ obshheteoreticheskom $\mathrm{i}$ sopostavitel'nom plane [Cognitive-pragmatic aspects of the functioning of language and discourse in general theoretical and comparative terms]. Ed. E.N. Aznacheeva. Cheljabinsk, Publ. Izd-vo ChGU: 112-113.

11. Ryzhkova M.M. 2008. Peredacha pragmaticheskoj sostavljajushhej obraznyh frazeologicheskih edinic $\mathrm{v}$ publicisticheskom tekste (na materiale anglijskogo i russkogo jazykov) [Transfer of the pragmatic component of figurative phraseological units in a publicistic text (based on the material of English and Russian languages)]. Abstract. dis. ... cand. philol. sciences. Tjumen', 22 p.

12. Starostina Ju.S. 2007. Interpretacija lingvisticheskoj ocenki v terminah aksiologicheskih suzhdenij [Interpretation of linguistic assessment in terms of axiological judgments]. Vestnik Samarskogo gosudarstvennogo universiteta [Vestnik of Samara State University], 3 (53): 232-240.

13. Suchkova S.A. 1998. Substantivnoe slovosochetanie $\mathrm{s}$ predlogom OF v dinamike vyskazyvanija [Substantive phrase with the preposition OF in the dynamics of the statement]. Dis .... cand. philol. sciences, $152 \mathrm{p}$.

14. Shiganova G.A. 2014. Osnovnye principy sozdanija semantiko-grammaticheskogo slovarja frazeologicheskih predlogov [Basic principles of creating a semantic and grammatical dictionary of phraseological prepositions]. Problemy istorii, filologii, kul'tury [Problems of History, Philology and Cultur], 3(45): 269-271. 
15. Jepshtejn O.V. 2010. Pragmaticheskie osobennosti menasivnogo rechevogo akta v politicheskom diskurse (na materiale anglijskogo jazyka) [Pragmatic features of a changeable speech act in political discourse (based on the English language)]. Abstract dis.... cand. philol. sciences. Moskva, $20 \mathrm{p}$.

16. Girard B. 2020. Everyday Life in China under the Shadow of Coronavirus. Available at: https://thediplomat.com/2020/02/everyday-life-in-china-under-the-shadow-of-coronavirus (accessed: 18 February 2020).

17. Kulchitskaya D.Yu. 2014. Multimedia text in journalism: an analysis of Russian and American mass media. In: World of Media. Yearbook of Russian Media and Journalism Studies: Ed. E.L. Vartanova, Moscow, Lomonosov Moscow State University: 265-275.

\section{ИНФОРМАЦИЯ ОБ АВТОРЕ}

Храброва Валентина Евгеньевна, старший преподаватель департамента иностранных языков Национально-исследовательского университета «Высшая школа экономики» Санкт-Петербург, г. Санкт-Петербург, Россия

\section{INFORMATION ABOUT THE AUTHOR}

Valentina E. Khrabrova, Senior Lecturer, Department of Foreign Languages, National Research University Higher School of Economics - St. Petersburg, St. Petersburg, Russia 